\title{
Relações lineares entre caracteres de nabo forrageiro e de tremoço branco
}

\author{
Linear relations among characters of forage turnips and of white lupine
}

\author{
Alberto Cargnelutti Filho ${ }^{\mathrm{I}}$ Marcos Toebe ${ }^{\mathrm{II}}$ Cláudia Burin'II ${ }^{\mathrm{II}}$ Bruna Mendonça Alves ${ }^{\mathrm{II}}$ \\ Giovani Facco ${ }^{\mathrm{II}}$ Gabriele Casarotto ${ }^{\mathrm{II}}$
}

RESUMO

O objetivo deste trabalho foi avaliar as relações entre caracteres de nabo forrageiro (Raphanus sativus L.) e de tremoço branco (Lupinus albus L.), e identificar caracteres para a seleção indireta. Foi conduzido um experimento com nabo forrageiro e outro com tremoço branco, em Santa Maria, Estado do Rio Grande do Sul (latitude $29^{\circ} 42^{\prime}$ S, longitude 5349'W e 95m de altitude). $\mathrm{Na}$ colheita, foram mensurados a altura de planta, o diâmetro de caule, o número de folhas e as massas verde e seca de parte aérea em 300 plantas de nabo forrageiro e a altura de planta, o diâmetro de caule, o número de vagens e as massas verde e seca de parte aérea em 400 plantas de tremoço branco. Foi investigada a relação entre os caracteres por meio de diagramas de dispersão e análises de correlação e de trilha. Na cultura de nabo forrageiro, o diâmetro de caule tem relação linear positiva com as massas verde e seca e pode ser utilizado para seleção indireta. Na cultura de tremoço branco, o número de vagens por planta tem relação linear positiva com as massas verde e seca e pode ser utilizado para seleção indireta.

Palavras-chave: Raphanus sativus L., Lupinus albus L., análise de trilha, seleção indireta.

\section{ABSTRACT}

The objective of this paper was to evaluate the relationships among characters in forage turnips (Raphanus sativus L.) and white lupine (Lupinus albus L.), and identify character for indirect selection. An experiment was conducted with forage turnips and another with white lupine, in Santa Maria, Rio Grande do Sul State, Brazil (latitude 2942'S, longitude 5349'W and $95 \mathrm{~m}$ altitude). At harvest, were measured plant height, stem diameter, leaf number and fresh and dry masses of shoots in 300 plants of forage turnips and plant height, stem diameter, number of pods and the fresh and dry masses of shoots in 400 plants of white lupine. It was studied the relationship among the traits by scatter plots, correlation and path analysis. In the culture of forage turnips the stem diameter has a positive linear relationship with the fresh and dry masses of shoots and can be used for indirect selection. In the culture of white lupine the number of pods has a positive linear relationship with the fresh and dry masses of shoots and can be used for indirect selection.

Key words: Raphanus sativus L., Lupinus albus L., path analysis, indirect selection.

\section{INTRODUÇÃO}

Por apresentarem elevada produção de massas verde e seca, na fase de florescimento, as culturas de nabo forrageiro (Raphanus sativus L.) e de tremoço branco (Lupinus albus L.) têm sido utilizadas em sistemas de rotação de culturas. Produções de massa seca de parte aérea de nabo forrageiro de $2.938 \mathrm{~kg} \mathrm{ha}^{-1}$ (CRUSCIOL et al., 2005) no estádio de pré-florescimento; $5.480,5 \mathrm{~kg} \mathrm{ha}$ ha $^{-1}$ (LIMA et al., 2007) quando as plantas atingiram $50 \%$ de florescimento; e $5.290 \mathrm{~kg} \mathrm{ha}^{-1}$ (CARNEIRO et al., 2008) e $5.586 \mathrm{~kg} \mathrm{ha}^{-1}$ (HEINZ et al., 2011) no florescimento, têm sido relatadas. Em tremoço branco, BARRADAS et al. (2001) verificaram que a massa seca oscilou entre $1.010 \mathrm{~kg} \mathrm{ha}^{-1}$ e $9.540 \mathrm{~kg} \mathrm{ha}^{-1}$, em função da cultivar, da época de semeadura e do momento de avaliação, em dias após a semeadura. Com base em 87 amostras de tremoço branco, coletadas de vários experimentos, BORKERT et al.

\footnotetext{
IDepartamento de Fitotecnia, Centro de Ciências Rurais (CCR), Universidade Federal de Santa Maria (UFSM), 97105-900, Santa Maria, RS, Brasil. E-mail: alberto.cargnelutti.filho@gmail.com. Autor para correspondência.

"Programa de Pós-graduação em Agronomia, UFSM, Santa Maria, RS, Brasil.

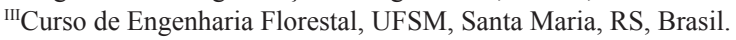


(2003) obtiveram média de $10.114 \mathrm{~kg} \mathrm{ha}^{-1}$ de massa seca, sendo que, em 22 amostras, a massa seca foi inferior a $7.000 \mathrm{~kg} \mathrm{ha}^{-1}$, em 20 , foi superior a $13.000 \mathrm{~kg}$ $\mathrm{ha}^{-1} \mathrm{e}$ as demais 45 amostras apresentaram massa seca intermediária.

Diferentemente do melhoramento genético da maioria das culturas comerciais que visam ao aumento da produtividade de grãos, nas plantas de cobertura de solo, normalmente, o maior interesse é em relação à quantidade de massa produzida. Embora o objetivo principal seja a seleção de plantas com maior produção de massa, em geral, é necessário a condução das plantas até o final do ciclo, a fim de obter material propagativo (sementes) para as gerações seguintes ou para a multiplicação. Considerando que a quantificação das massas verde e seca é de caráter destrutivo, é importante conhecer as relações dessas massas com outros caracteres que possam ser mensurados de modo não destrutivo, e utilizados na seleção indireta.

O grau de relacionamento entre dois caracteres pode ser mensurado por meio do coeficiente de correlação linear de Pearson (r) e este varia entre -1 (correlação linear negativa perfeita) e 1 (correlação linear positiva perfeita). Havendo mais de dois caracteres em estudo, a análise de trilha é apropriada e fornece informações importantes sobre as interrelações entre os caracteres. Na análise de trilha, os coeficientes de correlação são desdobrados em efeitos diretos e indiretos, o que permite medir a influência de uma variável sobre a outra, independentemente das demais (CRUZ \& CARNEIRO, 2003). Assim, é importante aplicar esses procedimentos estatísticos para identificar verdadeiras relações de causa e efeito entre caracteres. Caracteres com relação de causa e efeito podem ser usados na seleção de plantas.

Estudos de relações em caracteres de crambe (Crambe abyssinica Hochst) indicaram que o número de frutos por planta tem relação linear positiva com a produtividade de grãos e pode ser utilizado para seleção indireta (CARGNELUTTI FILHO et al., 2010). No entanto, não foram encontrados estudos de relações de caracteres que podem ser mensurados sem a destruição das plantas com as massas verde e seca de nabo forrageiro e de tremoço branco. Assim, o objetivo deste trabalho foi avaliar as relações entre caracteres de nabo forrageiro e de tremoço branco, e identificar caracteres para a seleção indireta.

\section{MATERIAL E MÉTODOS}

Foram realizados dois experimentos em área experimental do Departamento de Fitotecnia da
Universidade Federal de Santa Maria, Santa Maria, Estado do Rio Grande do Sul (latitude 29\%42'S, longitude $53^{\circ} 49^{\prime} \mathrm{W}$ e $95 \mathrm{~m}$ de altitude). O primeiro foi conduzido com a cultura de nabo forrageiro (Raphanus sativus L.) em uma área experimental de tamanho $15 \mathrm{~m} \times 15 \mathrm{~m}\left(225 \mathrm{~m}^{2}\right)$. A área experimental foi composta de 75 fileiras de $15 \mathrm{~m}$ de comprimento, espaçadas de $0,20 \mathrm{~m}$. A semeadura foi realizada em 10 de junho de 2010, e a densidade foi ajustada para 15 plantas por metro linear (750.000 plantas ha $\left.{ }^{-1}\right)$. A adubação de base foi de $30 \mathrm{~kg} \mathrm{ha}^{-1}$ de $\mathrm{N}, 150 \mathrm{~kg} \mathrm{ha}^{-1}$ de $\mathrm{P}_{2} \mathrm{O}_{5}$ e $150 \mathrm{~kg} \mathrm{ha}^{-1}$ de $\mathrm{K}_{2} \mathrm{O}$. Aos 28 dias após a emergência, foram aplicados $100 \mathrm{~kg}$ de $\mathrm{N} \mathrm{ha}^{-1}$. Na área experimental, foram selecionadas, aleatoriamente, 300 plantas. Nessas 300 plantas, aos 91 dias após a semeadura, ou seja, na fase de pleno florescimento do nabo forrageiro, foram mensurados os seguintes caracteres: altura de planta (APNF, considerando a distância da superfície do solo até a inserção da última folha), em cm; diâmetro de caule (DCNF, medido a $5 \mathrm{~cm}$ da superfície do solo com auxílio de paquímetro), em $\mathrm{mm}$; número de folhas (NFNF); massa verde de parte aérea (MVNF), em g planta ${ }^{-1}$; e massa seca de parte aérea (MSNF), em g planta ${ }^{-1}$.

O segundo experimento foi conduzido com a cultura de tremoço branco (Lupinus albus L.) numa área experimental de $50 \mathrm{~m} \times 50 \mathrm{~m}$. A semeadura do tremoço branco foi realizada a lanço, no dia 13 de junho de 2011. A adubação de base foi de $30 \mathrm{~kg} \mathrm{ha}^{-1}$ de N, $120 \mathrm{~kg} \mathrm{ha}^{-1}$ de $\mathrm{P}_{2} \mathrm{O}_{5}$ e $120 \mathrm{~kg} \mathrm{ha}^{-1}$ de $\mathrm{K}_{2} \mathrm{O}$. Em 17 de novembro de 2011 (157 dias após a semeadura), foram coletadas, na área experimental, aleatoriamente, 400 plantas. A população nesse momento era de 146.667 plantas ha ${ }^{-1}$. Em cada uma das 400 plantas, foram mensurados os seguintes caracteres: altura de planta (APTB, considerando a distância da superfície do solo até a inserção da última folha), em cm; diâmetro de caule (DCTB, medido na superfície do solo com auxílio de paquímetro), em mm; número de vagens (NVTB); massa verde de parte aérea (MVTB), em g planta-1; e massa seca de parte aérea (MSTB), em g planta ${ }^{-1}$.

Para cada um dos 10 caracteres, foram calculados a média e o coeficiente de variação. A seguir, para visualizar as relações entre os caracteres de nabo forrageiro (APNF, DCNF, NFNF, MVNF e MSNF) e de tremoço branco (APTB, DCTB, NVTB, MVTB e MSTB), foram feitos diagramas de dispersão. Após, para cada cultura, foi calculada a matriz de coeficientes de correlação linear de Pearson (r) entre os caracteres e, por meio do teste t de Student, a 5\% de probabilidade de erro, foi verificada a significância do $\mathrm{r}$.

A seguir, em cada matriz de coeficientes de correlação linear de Pearson (r), foi realizado 
o diagnóstico de multicolinearidade (CRUZ \& CARNEIRO, 2003) e interpretado de acordo com critério de MONTGOMERY \& PECK (1982). Depois disso, na cultura de nabo forrageiro, foram realizadas análises de trilha (path analysis) das variáveis principais (MVNF e MSNF) em função das variáveis explicativas (APNF, DCNF e NFNF). A seguir, na cultura de tremoço branco, foram realizadas análises de trilha das variáveis principais (MVTB e MSTB) em função das variáveis explicativas (APTB, DCTB e NVTB). As análises estatísticas foram realizadas com o auxílio do programa GENES (CRUZ, 2006) e do aplicativo Office Excel ${ }^{\circledR}$.

\section{RESULTADOS E DISCUSSÃO}

As médias dos caracteres mensurados em 300 plantas de nabo forrageiro e em 400 plantas de tremoço branco (Tabela 1) revelaram adequado desenvolvimento das plantas das duas culturas. Resultados próximos a esses foram relatados para as culturas de nabo forrageiro (CRUSCIOL et al., 2005; LIMA et al., 2007; CARNEIRO et al., 2008; HEINZ et al., 2011) e de tremoço branco (BARRADAS et al., 2001; BORKERT et al., 2003). Diferenças na produtividade de massa seca entre experimentos podem ser atribuídas às condições climáticas, ao solo, às cultivares ou ao estágio em que as plantas foram manejadas (HEINZ et al., 2011).

Entre os caracteres de nabo forrageiro, a magnitude do coeficiente de variação $(\mathrm{CV})$ oscilou entre $18,53 \%$ para a altura de planta e $68,10 \%$ para a massa seca de parte aérea (Tabela 1). Em relação aos caracteres de tremoço branco, o $\mathrm{CV}$ variou entre $12,54 \%$ para a altura de planta e $51,83 \%$ para a massa seca de parte aérea. Maior variabilidade de caracteres produtivos, como a produtividade de grãos (CV=61,95716\%), em relação aos morfológicos, como a altura de planta $(\mathrm{CV}=19,53659 \%)$, também foi verificada na cultura de crambe (CARGNELUTTI FILHO et al., 2010). Essa variabilidade existente é importante e confere adequabilidade ao estudo das relações entre os caracteres, por meio das análises de correlação e de trilha.

Os diagramas de dispersão, entre os caracteres de nabo forrageiro (Figura 1) e de tremoço branco (Figura 2), revelam padrões de linearidade entre os caracteres. Então, diante das considerações, em relação ao adequado desenvolvimento das plantas, a ampla variabilidade dos dados e a existência de padrões de linearidade, aliado ao elevado número de plantas avaliadas, pode-se inferir que esse banco de dados oferece credibilidade ao estudo de relações lineares entre esses caracteres.

Os coeficientes de correlação linear de Pearson (r) entre os caracteres de nabo forrageiro $(0,4494 \leq \mathrm{r} \leq 0,9671)$ e de tremoço branco $(0,4206 \leq r \leq 0,9828) \quad$ (Tabela 1$)$ revelam associações lineares positivas e confirmam a existência de padrões de linearidade (Figuras 1 e 2). As massas verde e seca de parte aérea de nabo forrageiro apresentaram maior grau de associação linear (maiores valores de r)

Tabela 1 - Média, coeficiente de variação (CV) e estimativas dos coeficientes de correlação linear de Pearson entre caracteres mensurados em 300 plantas de nabo forrageiro (Raphanus sativus L.) e em 400 plantas de tremoço branco (Lupinus albus L.).

\begin{tabular}{|c|c|c|c|c|c|c|c|}
\hline Carateres $^{(1)}$ & Média & $\mathrm{CV}(\%)$ & APNF & DCNF & NFNF & MVNF & MSNF \\
\hline & & & ----Nal & geiro-------- & & & \\
\hline APNF & 86,40 & 18,53 & 1 & $0,5512 *$ & $0,4494 *$ & $0,6013 *$ & $0,5922 *$ \\
\hline DCNF & 9,03 & 27,94 & $0,5512^{*}$ & 1 & $0,4665^{*}$ & $0,8492 *$ & $0,8131 *$ \\
\hline NFNF & 7,30 & 26,64 & $0,4494 *$ & $0,4665^{*}$ & 1 & $0,4752 *$ & $0,4776^{*}$ \\
\hline MVNF & 52,06 & 62,03 & $0,6013^{*}$ & $0,8492 *$ & $0,4752 *$ & 1 & $0,9671 *$ \\
\hline \multirow[t]{3}{*}{ MSNF } & 5,16 & 68,10 & $0,5922^{*}$ & $0,8131 *$ & $0,4776^{*}$ & $0,9671 *$ & 1 \\
\hline & & & ----Tre & anco------ & - & - & 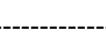 \\
\hline & Média & $\mathrm{CV}$ & АРTB & DCTB & NVTB & MVTB & MSTB \\
\hline АРТВ & 105,96 & 12,54 & 1 & $0,4256^{*}$ & $0,4206^{*}$ & $0,5321 *$ & $0,5387^{*}$ \\
\hline DCTB & 11,45 & 22,55 & $0,4256^{*}$ & 1 & $0,7719 *$ & $0,8304 *$ & $0,8460 *$ \\
\hline NVTB & 26,14 & 47,58 & $0,4206^{*}$ & $0,7719 *$ & 1 & $0,9278 *$ & $0,9182 *$ \\
\hline MVTB & 337,23 & 50,82 & $0,5321 *$ & $0,8304 *$ & $0,9278 *$ & 1 & $0,9828^{*}$ \\
\hline MSTB & 54,55 & 51,83 & $0,5387^{*}$ & $0,8460 *$ & $0,9182 *$ & $0,9828 *$ & 1 \\
\hline
\end{tabular}

(1) Caracteres de nabo forrageiro: APNF, altura de planta, em cm; DCNF, diâmetro de caule, em mm; NFNF, número de folhas; MVNF, massa verde de parte aérea, em g planta ${ }^{-1}$; e MSNF, massa seca de parte aérea, em g planta ${ }^{-1}$. Caracteres de tremoço branco: APTB, altura de planta, em cm; DCTB, diâmetro de caule, em mm; NVTB, número de vagens; MVTB, massa verde de parte aérea, em g planta ${ }^{-1}$; e MSTB, massa seca de parte aérea, em g planta ${ }^{-1}{ }^{*}$ Significativo a $5 \%$ de probabilidade de erro pelo teste $t$. 


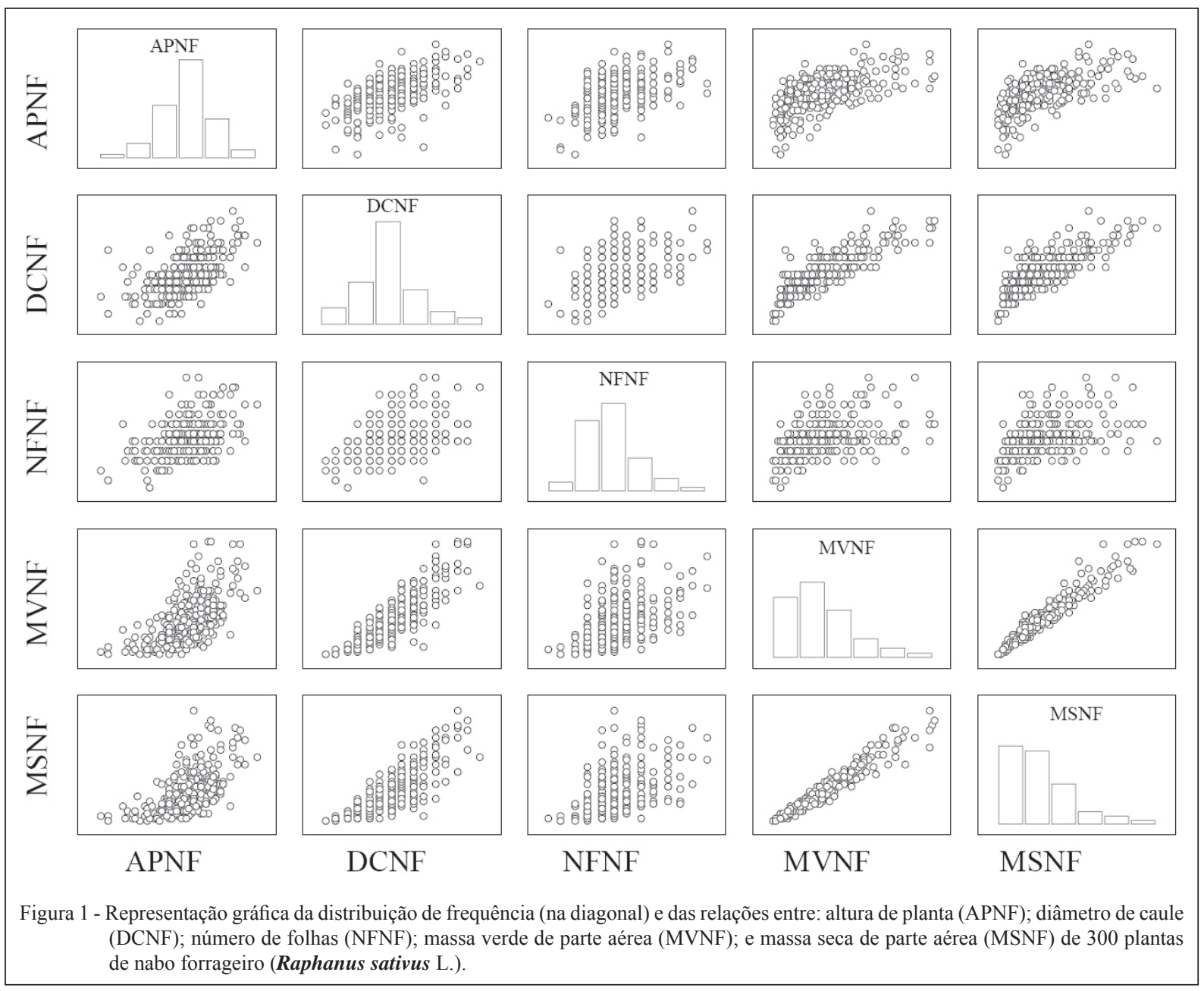

com diâmetro de caule, menor grau de associação (menores valores de r) com o número de folhas e grau intermediário de associação com a altura de planta (Tabela 1). Na cultura de tremoço branco, as massas verde e seca de parte aérea apresentaram maior grau de associação linear com o número de vagens, comparada com o diâmetro de caule e altura de planta, que apresentaram, respectivamente, graus de associação linear intermediário e menor (Tabela 1). Portanto, esses resultados sugerem que plantas de nabo forrageiro com maior diâmetro e plantas de tremoço branco com maior número de vagens estão associadas a plantas com maiores massas verde e seca de parte aérea. No entanto, apenas por meio dos coeficientes de correlação, não é possível inferir qual dos caracteres tem efeito direto nas massas verde e seca de parte aérea de nabo forrageiro e de tremoço branco. Assim, a análise de trilha é um procedimento adequado para inferir sobre as verdadeiras relações entre os caracteres.
O diagnóstico de multicolinearidade na matriz de coeficientes de correlação linear de Pearson, entre as variáveis explicativas altura de planta (APNF), diâmetro de caule (DCNF) e número de folhas (NFNF) de nabo forrageiro, revelou número de condição (NC) igual a 4,42 (Tabela 2). Entre as variáveis explicativas altura de planta (APTB), diâmetro de caule (DCTB) e número de vagens (NVTB) de tremoço branco, o NC foi igual a 9,20 (Tabela 3). Esses resultados classificam as matrizes como de colinearidade baixa, conforme critério de MONTGOMERY \& PECK (1982). Assim, as análises de trilha das massas verde (MVNF) e seca de parte aérea (MSNF) de nabo forrageiro em função das variáveis explicativas APNF, DCNF e NFNF e das massas verde (MVTB) e seca de parte aérea (MSTB) de tremoço branco, em função das variáveis explicativas APTB, DCTB e NVTB, podem ser realizadas adequadamente (CRUZ, 2006). 


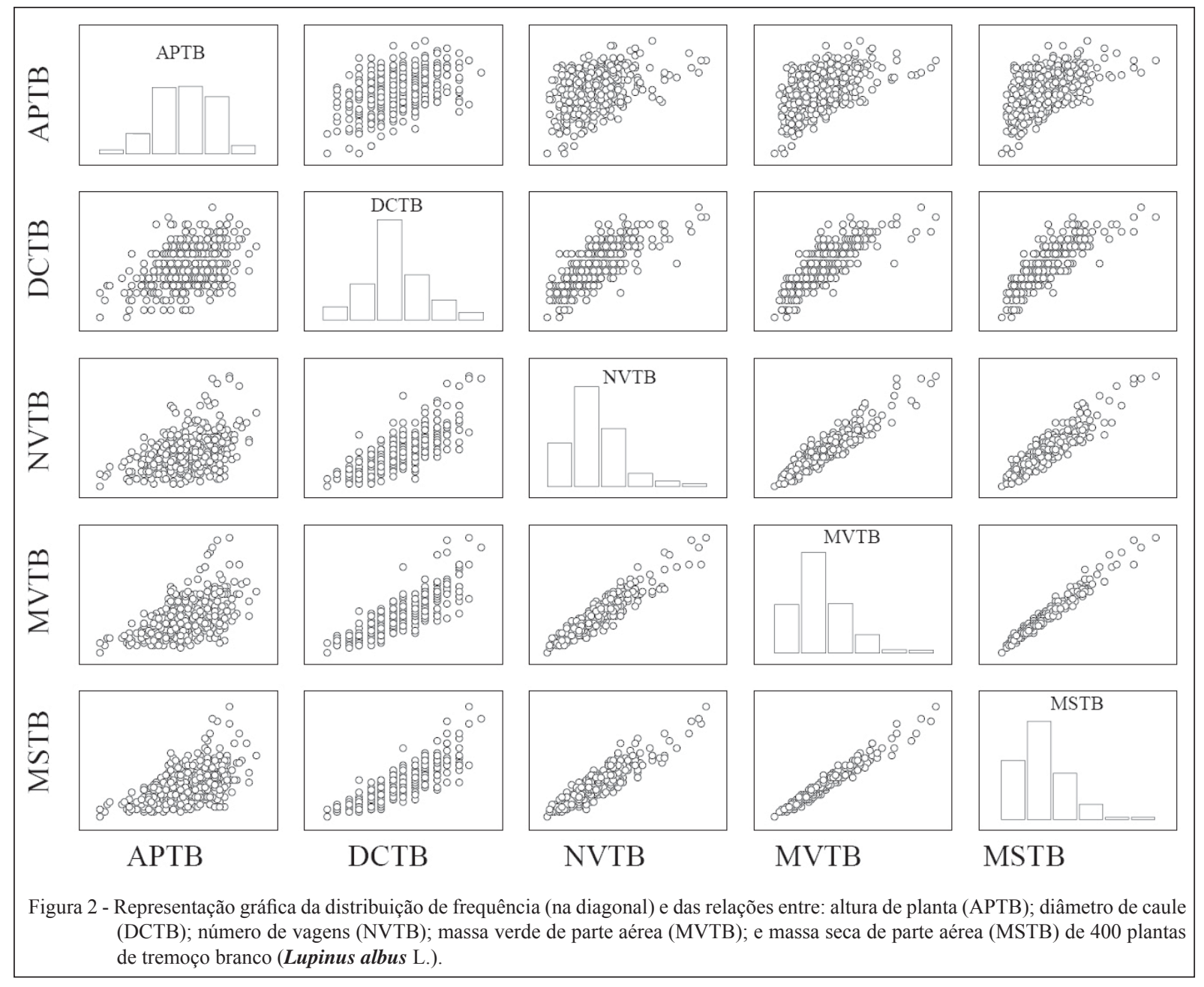

$\mathrm{Na}$ cultura de nabo forrageiro, a massa verde de parte aérea (MVNF) apresentou correlação linear positiva $(\mathrm{r}=0,8492)$ e efeito direto $(0,7255)$ com mesmo sinal e de magnitude semelhante com o diâmetro de caule (DCNF), o que explica a verdadeira associação existente (Tabela 2). Assim, pode-se inferir que as plantas com maior diâmetro de caule são aquelas com maior massa verde de parte aérea. Em menor magnitude, a MVNF apresentou associação linear com a APNF $(r=0,6013)$ e o NFNF $(r=0,4752)$. No entanto, os efeitos diretos da APNF $(0,1754)$ e do NFNF $(0,0579)$ sobre a MVNF foram desprezíveis e, portanto, a associação existente é explicada pelos maiores efeitos indiretos via $\mathrm{DCNF}$ ( $\mathrm{APNF}=0,3999$; $\mathrm{NFNF}=0,3384)$. Em relação à massa seca de parte aérea (MSNF), os resultados foram semelhantes, o que pode ser explicado pela forte associação linear ( $r=9671$ ) entre MVNF e MSNF (Tabela 1). Portanto, pode-se inferir que a seleção indireta para a MVNF e a MSNF deve ser realizada com base no DCNF.
$\mathrm{Na}$ cultura de tremoço branco, a massa verde de parte aérea (MVTB) apresentou correlação linear positiva $(r=0,9278)$ e efeito direto $(0,6773)$ com mesmo sinal e de magnitude semelhante com o número de vagens (NVTB), o que evidencia relação de causa e efeito entre esses caracteres (Tabela 3). Assim, pode-se inferir que as plantas com maior número de vagens são aquelas com maior massa verde de parte aérea. Em menor magnitude, a MVTB apresentou associação linear com o DCTB $(\mathrm{r}=0,8304)$ e a APTB $(r=0,5321)$. Porém, os efeitos diretos do DCTB $(0,2472)$ e da APTB $(0,1420)$ sobre a MVTB foram inferiores, o que demonstra não haver relação de causa e efeito, e, portanto, a associação existente é explicada pelos maiores efeitos indiretos via NVTB (DCTB=0,5228; $\mathrm{APTB}=0,2849$ ). Em função da forte associação linear $(r=9828)$ entre MVTB e MSTB (Tabela 1), o mesmo raciocínio pode ser realizado em relação à massa seca de parte aérea (MSTB). Assim, pode-se inferir que a seleção indireta para a MVTB e a MSTB deve ser realizada com base no NVTB. 
Tabela 2 - Estimativas dos coeficientes de correlação linear de Pearson e dos efeitos diretos e indiretos dos caracteres altura de planta (APNF), diâmetro de caule (DCNF) e número de folhas (NFNF) sobre a massa verde de parte aérea (MVNF) e a massa seca de parte aérea (MSNF) de nabo forrageiro (Raphanus sativus L.).

\begin{tabular}{lll}
\hline & & \\
Efeito & MVNF & MSNF \\
\hline Direto de APNF sobre & 0,1754 & 0,1848 \\
Indireto de APNF via DCNF & 0,3999 & 0,3714 \\
Indireto de APNF via NFNF & 0,0260 & 0,0361 \\
Correlação de Pearson (r) & $0,6013 *$ & $0,5922^{*}$ \\
& & \\
Direto de DCNF sobre & 0,7255 & 0,6738 \\
Indireto de DCNF via APNF & 0,0967 & 0,1018 \\
Indireto de DCNF via NFNF & 0,0270 & 0,0374 \\
Correlação de Pearson (r) & $0,8492 *$ & $0,8131^{*}$ \\
& & \\
Direto de NFNF sobre & 0,0579 & 0,0802 \\
Indireto de NFNF via APNF & 0,0788 & 0,0830 \\
Indireto de NFNF via DCNF & 0,3384 & 0,3143 \\
Correlação de Pearson (r) & $0,4752 *$ & $0,4776^{*}$ \\
& & \\
Coeficiente de determinação & 0,7491 & 0,6956 \\
Variável residual & 0,5009 & 0,5517 \\
Número de condição & 4,42 & 4,42 \\
\hline
\end{tabular}

* Significativo a $5 \%$ de probabilidade de erro pelo teste $\mathrm{t}$, com 298 graus de liberdade.

$\mathrm{Na}$ prática, esses resultados evidenciam que é possível selecionar as plantas de nabo forrageiro e de tremoço branco na área experimental, por meio, respectivamente, da medição do diâmetro de caule e da contagem do número de vagens, sem a necessidade de destruir as plantas para a colheita. Esse fato é importante, pois possibilita selecionar as plantas com maiores massas verde e seca de parte aérea e ainda avaliar a produtividade de grãos delas.

\section{CONCLUSÃO}

$\mathrm{Na}$ cultura de nabo forrageiro (Raphanus sativus L.), o diâmetro de caule tem relação linear positiva com as massas verde e seca e pode ser utilizado para seleção indireta. Na cultura de tremoço branco (Lupinus albus L.), o número de vagens por planta tem relação linear positiva com as massas verde e seca e pode ser utilizado para seleção indireta.

\section{AGRADECIMENTOS}

Ao Conselho Nacional de Desenvolvimento Científico e Tecnológico $(\mathrm{CNPq})$ e à Coordenação de Aperfeiçoamento de
Tabela 3 - Estimativas dos coeficientes de correlação linear de Pearson e dos efeitos diretos e indiretos dos caracteres altura de planta (APTB), diâmetro de caule (DCTB) e número de vagens (NVTB) sobre a massa verde de parte aérea (MVTB) e a massa seca de parte aérea (MSTB) de tremoço branco (Lupinus albus L.).

\begin{tabular}{lll}
\hline & & \\
Efeito & MVTB & MSTB \\
\hline Direto de APTB sobre & 0,1420 & 0,1481 \\
Indireto de APTB via DCTB & 0,1052 & 0,1288 \\
Indireto de APTB via NVTB & 0,2849 & 0,2618 \\
Correlação de Pearson (r) & $0,5321^{*}$ & $0,5387^{*}$ \\
& & \\
Direto de DCTB sobre & 0,2472 & 0,3026 \\
Indireto de DCTB via APTB & 0,0604 & 0,0630 \\
Indireto de DCTB via NVTB & 0,5228 & 0,4803 \\
Correlação de Pearson (r) & $0,8304 *$ & $0,8460^{*}$ \\
& & \\
Direto de NVTB sobre & 0,6773 & 0,6223 \\
Indireto de NVTB via APTB & 0,0597 & 0,0623 \\
Indireto de NVTB via DCTB & 0,1908 & 0,2336 \\
Correlação de Pearson (r) & $0,9278^{*}$ & $0,9182 *$ \\
& & \\
Coeficiente de determinação & 0,9092 & 0,9072 \\
Variável residual & 0,3013 & 0,3047 \\
Número de condição & 9,20 & 9,20 \\
\hline
\end{tabular}

Significativo a $5 \%$ de probabilidade de erro pelo teste t, com 398 graus de liberdade.

Pessoal de Nível Superior (CAPES), pelas bolsas concedidas. À Fundação de Amparo à Pesquisa do Estado do Rio Grande do Sul (FAPERGS), pelo auxílio financeiro.

\section{REFERÊNCIAS}

BARRADAS, C.A.A. et al. Comportamento de adubos verdes de inverno na região serrana fluminense. Pesquisa Agropecuária Brasileira, v.36, p.1461-1468, 2001. Disponível em: <http:// www.scielo.br/pdf/pab/v36n12/7488.pdf>. Acesso em: 28 abr. 2012. doi: 10.1590/S0100-204X2001001200003.

BORKERT, C.M. et al. Nutrientes minerais na biomassa da parte aérea em culturas de cobertura de solo. Pesquisa Agropecuária Brasileira, v.38, p.143-153, 2003. Disponível em: $<$ http://www. scielo.br/pdf/pab/v38n1/a19v38n1.pdf>. Acesso em: 28 abr. 2012. doi: $10.1590 / \mathrm{S} 0100-204 \mathrm{X} 2003000100019$

CARGNELUTTI FILHO, A. et al. Tamanho de amostra e relações lineares de caracteres morfológicos e produtivos de crambe. Ciência Rural, v.40, p.2262-2267, 2010. Disponível em: $<$ http:// www.scielo.br/pdf/cr/v40n11/a774cr3308.pdf>. Acesso em: 28 abr. 2012. doi: 10.1590/S0103-84782010001100003.

CARNEIRO, M.A.C. et al. Produção de fitomassa de diferentes espécies de cobertura e suas alterações na atividade microbiana de solo de cerrado. Bragantia, v.67, p.455-462, 2008. Disponível em: <http://www.scielo.br/pdf/brag/v67n2/ 
a21v67n2.pdf>. Acesso em: 28 abr. 2012. doi: 10.1590/S000687052008000200021 .

CRUSCIOL, C.A.C. et al. Persistência de palhada e liberação de nutrientes do nabo forrageiro no plantio direto. Pesquisa Agropecuária Brasileira, v.40, p.161-168, 2005. Disponível em: $<$ http://www.scielo.br/pdf/pab/v40n2/23823.pdf>. Acesso em: 28 abr. 2012. doi: 10.1590/S0100-204X2005000200009.

CRUZ, C.D.; CARNEIRO, P.C.S. Modelos biométricos aplicados ao melhoramento genético. Viçosa: UFV, 2003. V.2. 585p.

CRUZ, C.D. Programa genes: estatística experimental e matrizes. Viçosa: UFV, 2006. 285p.
HEINZ, R. et al. Decomposição e liberação de nutrientes de resíduos culturais de crambe e nabo forrageiro. Ciência Rural, v.41, p.1549-1555, 2011. Disponível em: <http://www.scielo.br/ pdf/cr/v41n9/a11611cr5315.pdf >. Acesso em: 28 abr. 2012. doi: 10.1590/S0103-84782011000900010.

LIMA, J.D. et al. Comportamento do nabo forrageiro (Raphanus sativus L.) e da nabiça (Raphanus raphanistrum L.) como adubo verde. Pesquisa Agropecuária Tropical, v.37, p.60-63, 2007. Disponível em: <http://www.revistas.ufg.br/index.php/pat/article/ download/1871/1778>. Acesso em: 28 abr. 2012.

MONTGOMERY, D.C.; PECK, E.A. Introduction to linear regression analysis. New York: John Wiley \& Sons, 1982. 504p. 